\title{
EINE SCHRIFT DER REITERNOMADEN IM 1. JT. V. CHR.? BEMERKUNGEN ZU DEN SOGENANNTEN SKYTHISCHEN PFEILSPITZEN MIT MARKIERUNGEN ZWISCHEN OSTALPEN, URAL UND ANATOLIEN
}

\author{
Anja Hellmuth Kramberger - Radoslav Čambal
}

DOI: https://doi.org/10.31577/szausav.2019.suppl.1.11

Keywords: Iron Age, Smolenice-Molpir, equestrian nomads, Scythian arrowheads

\begin{abstract}
A script of the equestrian nomads in the $1^{\text {st }}$ millennium BC? Remarks on the so-called Scythian arrowheads with markings between Eastern Alps, Urals and Anatolia

Numerous studies are devoted to the distribution, chronology and historical interpretation of the so-called Scythian arrowheads, which are known in the vast area between Central Europe, Eurasia and the Near East. Less well known and researched so far is the occurrence of incised and cast signs that occur on the wings and sometimes the sockets of the two- and threewinged bronze arrowheads. While such signs on finds from the Northern Pontic region and Anatolia have been known for some time, their occurrence on arrowheads from eastern Central Europe, more precisely on arrowheads from the fortified Hallstatt-settlement Smolenice-Molpír, belongs to the more recent discoveries. While initially only a very small number of pieces with incised signs have been discovered and made public, we can now say that their number and their variety are much larger. The finds from Smolenice-Molpír are now among the largest ensembles of arrowheads with incised signs, which are known to date. With a view to comparable finds, the question arises of the interpretation of these signs - is it possibly a sign system that was widespread in the mounted nomadic cultural circle and is to be addressed as writing?
\end{abstract}

\section{EINLEITUNG}

Im Jahr 2002 wurden im Rahmen der Materialaufnahme für eine Magisterarbeit an der Freien Universität Berlin im Museum von Trnava (Slowakei) an einigen der sogenannten skythischen Pfeilspitzen aus der befestigten Höhensiedlung von Smolenice-Molpír in der Südwestslowakei kleine eingeritzte Zeichen entdeckt (Abb. 1; 2; Hellmuth 2006, 135 ff.; Abb. 107; Taf. 22: 1-5). Für eine der Pfeilspitzen (Abb. 1, Obere rechts) dokumentierte der Ausgräber von Smolenice-Molpír, M. Dušek, dass sie direkt in den Fugen zwischen den Steinen der Außenseite der Mauern steckte (Dušek, M./Dušek, S. 1984, 25, 219; Taf. 32; 43; Hellmuth 2006, Taf. 22: 2), sie also während eines Angriffs von außen auf die Befestigung abgeschossen worden war. Das feine eingeritzte Zeichen, das an eine Sanduhr mit fehlendem Boden erinnert, blieb von M. Dušek unentdeckt. Ähnliche eingeritzte Zeichen waren bis zu diesem Zeitpunkt in erster Linie aus Fundplätzen Anatoliens bekannt ${ }^{1}$ und aus Kurganen vom Mittleren Dnepr, ${ }^{2}$ dem Unteren Wolgagebiet ${ }^{3}$ bis zum südlichen $\mathrm{Ural}^{4}$ (Abb. 3).

1 Z. B. aus: Boğazköy - Boehmer 1972, Taf. 30: 895; 31: 907; Amasya - Ünal 1982, Abb. 5: 134; 6: 202-204; 7: 227; Ivantchik 2001, Abb. 23: 134, 202-204, 227.

2 Z. B. aus Basovka - Galanina 1997, Taf. 25: 18; Hellmuth 2010, Taf. 24: 18; Korniyvka - Polin 1987, Abb. 12: 26; Pridneprovka Il'ienskaja/Terenozhkin 1983, 105 obere Reihe; Hellmuth 2010, Taf. 184: 2, 4.

3 Z. B. aus: Aksjenovskij - Shilov/Ochir-Gorjeva 1997, Abb. 7, obere Reihe; 15, zweite Reihe von oben; 16, unterste Reihe; Hellmuth 2010, Taf. 4: 15-19; 5: 30-32; 8: 9-12; 11: 20-24, 33, 53, 54; Blumenfeld' - Smyrnov 1964, Abb. 11B: 4; Hellmuth 2010, Taf. 38: 13-16; Leninsk - Smyrnov 1964, Abb. 52: 7, 18; Kamyschin (?) - Rau 1929, Taf. 20: 1D; Nižnjego Povolž'ja - Dvornichenkol Plachov/Ochir-Gorjaeva 1997, Abb. 6, vierte Reihe Mitte; Hellmuth 2010, Taf. 148: 30.

4 Z. B. aus: Pjatmary - Smyrnov 1964, Abb. 26: 1; Südural - Smyrnov 1964, Abb. 37: 19; 39: 8; Lapasina - Smyrnov 1964, Abb. 43: 1a. 
Eine weitere Form der „Markierung“, die auf den sogenannten skythischen Pfeilspitzen beobachtet und deren Funktion in der Forschung diskutiert wurde (z. B. Alekseev 1992, 86; Daragan 2015; Eckhardt 1991, 147, Abb. 10; Ivantchik 2001, 49, Abb. 24; Yalçıkl 2009), ${ }^{5}$ stellen gegossene Zeichen dar (Abb. 6). Die Interpretation dieser Zeichen reicht von Handwerker- oder Besitzerzeichen, über eine "kultische" Bedeutung (Eckhardt 1991, 147; Hellmuth 2006, 136; Yalçıkl 2009) bis zur originellen Art der Dekorierung (Ivantchik 2001, 49).

Der vorliegende Beitrag möchte, basierend auf publiziertem und bislang unveröffentlichtem Material, einen Überblick über die Variationsbreite der geritzten und gegossen Zeichen auf den Pfeilspitzen vom sogenannten skythischen Typ zwischen Ostalpenraum, südlichem Ural und Anatolien bieten sowie einen neuen Ansatz zur Interpretation dieser Markierungen erörtern.

\section{PFEILSPITZEN MIT RITZZEICHEN}

\section{Smolenice-Molpír}

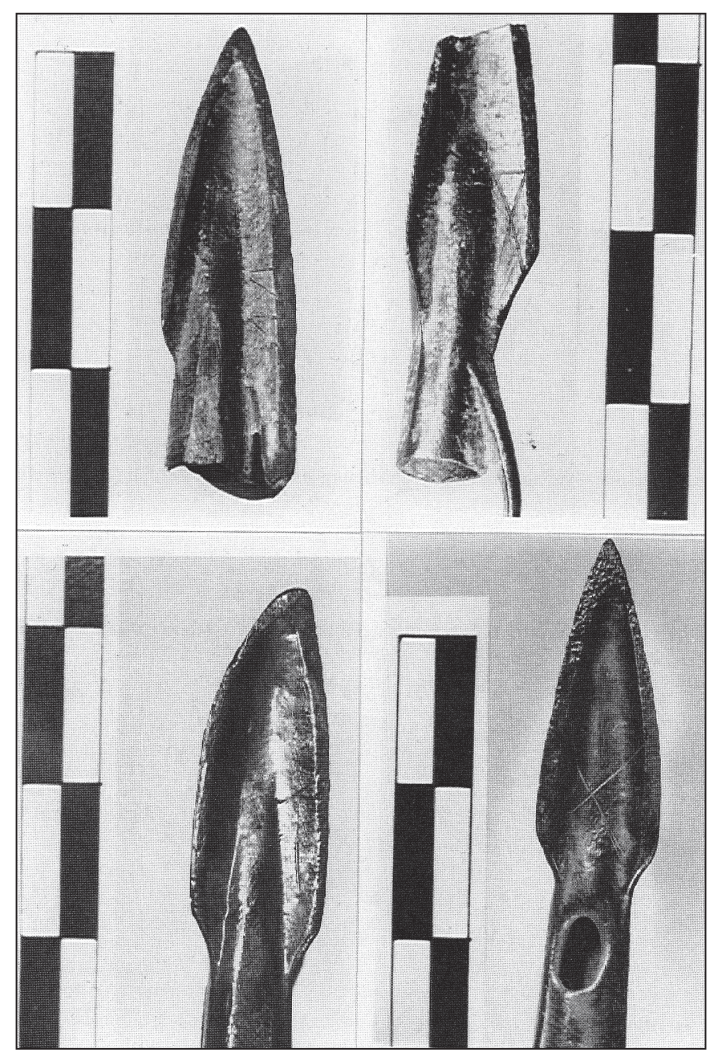

Abb. 1. Pfeilspitzen mit Ritzzeichen aus der befestigten hallstattzeitlichen Höhensiedlung von Smolenice-Molpír (nach Hellmuth 2006, Abb. 107).

Ausgangspunkt für unsere Betrachtungen zu den Pfeilspitzen mit eingeritzten Zeichen sollen die Funde aus der hallstattzeitlichen Siedlung von Smolenice-Molpír bilden, die den am weitesten westlich gelegenen Nachweis darstellen. Die an einem Ausläufer der Kleinen Karpaten in der westlichen Slowakei gelegene befestigte Höhensiedlung der Hallstattzeit wurde in den 60er und 70er Jahren des letzten Jahrhunderts durch umfangreiche Ausgrabungstätigkeiten unter der Leitung von M. Dušek untersucht und wurde der Fachwelt durch zahlreiche Publikationen bekannt gemacht ${ }^{6}$. Die Pfeilspitzen vom sogenannten skythischen Typ, die zu Hunderten während der Ausgrabungen geborgen wurden, nehmen dabei eine herausragende Position ein, da gezeigt werden konnte, dass sie nicht als Relikte von Stammeszwistigkeiten anzusehen sind (Dušek 1974, 148), sondern vielmehr mit der Ausbreitung reiternomadisch geprägter Völkerschaften aus dem eurasischen Steppenraum gen Westen in Zusammenhang stehen (Hellmuth 2010, 328 ff.; Hellmuth Kramberger 2017). Wie einleitend bemerkt, konnten an fünf Exemplaren aus den Grabungen Dušeks während der Neubearbeitung im Museum in Trnava im Jahr 2002 feine eingeritzte Zeichen entdeckt werden (Abb. 1; Hellmuth 2006, 135 ff.; Abb. 107; Taf. 22: 1-5). Unter den Zeichen, die allesamt an verschiedenen Varianten der dreiflügeligen Pfeilspitzen mit äußerer Schäftungstülle angebracht sind, konnten die Folgenden identifiziert werden (Abb. 2, von links nach rechts): ein Kreuz, ein (unvollständig) Sanduhr-förmiges Zeichen, zwei übereinander stehende nach rechts gerichtete Winkel, eine T-förmige Ritzung sowie eine schräg nach unten gerichtete Ritzung mit darunter sitzendem Winkel. Als Vergleiche für die kreuzförmigen Ritzungen wurde zunächst auf Funde von Pfeilspitzen aus einem beraubten Grab bei Amasya in der Umgebung von Ladik in Anatolien (Ivantchik 2001, Abb. 23: 134, 202; Hellmuth 2006, 137, Taf. 22: 7, 8) verwiesen, für die winkelförmigen Einritzungen auf ein Fundstück aus Boğazköy (Boehmer 1972, Taf. 31: 907; Hellmuth 2006, 137, Taf. 22: 9).

\footnotetext{
5 Ein Vortrag zu den Zeichen auf den skythischen Bronzepfeilspitzen wurde von O. Lifantii (Kiev) auf der Tagung Yalta vom 20.-23. 09. $2012 \mathrm{im}$ Rahmen des Humboldt Kollegs gehalten. Sieh auch: Lifantij 2011.

6 In Auswahl: Dušek, M./Dušek, S. 1984; 1995; Hellmuth 2006; Ludwig/Stegmann-Rajtár/Tirpák 2010; Müller 2012; Parzingerl Stegmann-Rajtár 1988; Stegmann-Rajtár 1998.
} 
Im Vergleich mit anderen eisenzeitlichen befestigten Siedlungen südlich und nördlich der Kleinen Karpaten nimmt die bis dato publizierte Anzahl von knapp 400 Stücken aus Smolenice-Molpír eine herausragende Position ein. Eine mit 234 Stücken größere Zahl an Pfeilspitzen kam bislang lediglich während neuerer Forschungen im nordostungarischen Fundplatz Verebce-bérc bei Dédestapolcsány zutage (Szabó/Czajlik/Remény 2014). Es muss jedoch angenommen werden - und wahrscheinlich gilt dies auch für andere Fundplätze mit Pfeilspitzen vom sogenannten skythischen Typ-, dass die bislang bekannten Pfeilspitzen aus Smolenice-Molpír nur einen Bruchteil dessen darstellen, was sich ursprünglich an Geschossspitzen am Platz befunden hat. Berichten der älteren

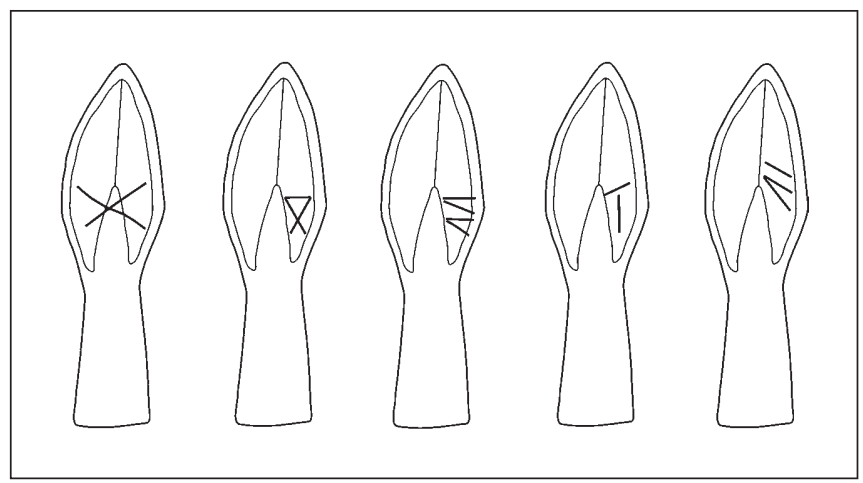

Abb. 2. Schematische Wiedergabe des dreiflügeligen Pfeilspitzen-Grundtyps mit den verschiedenen Zeichen aus der befestigten hallstattzeitlichen Höhensiedlung von SmoleniceMolpír.

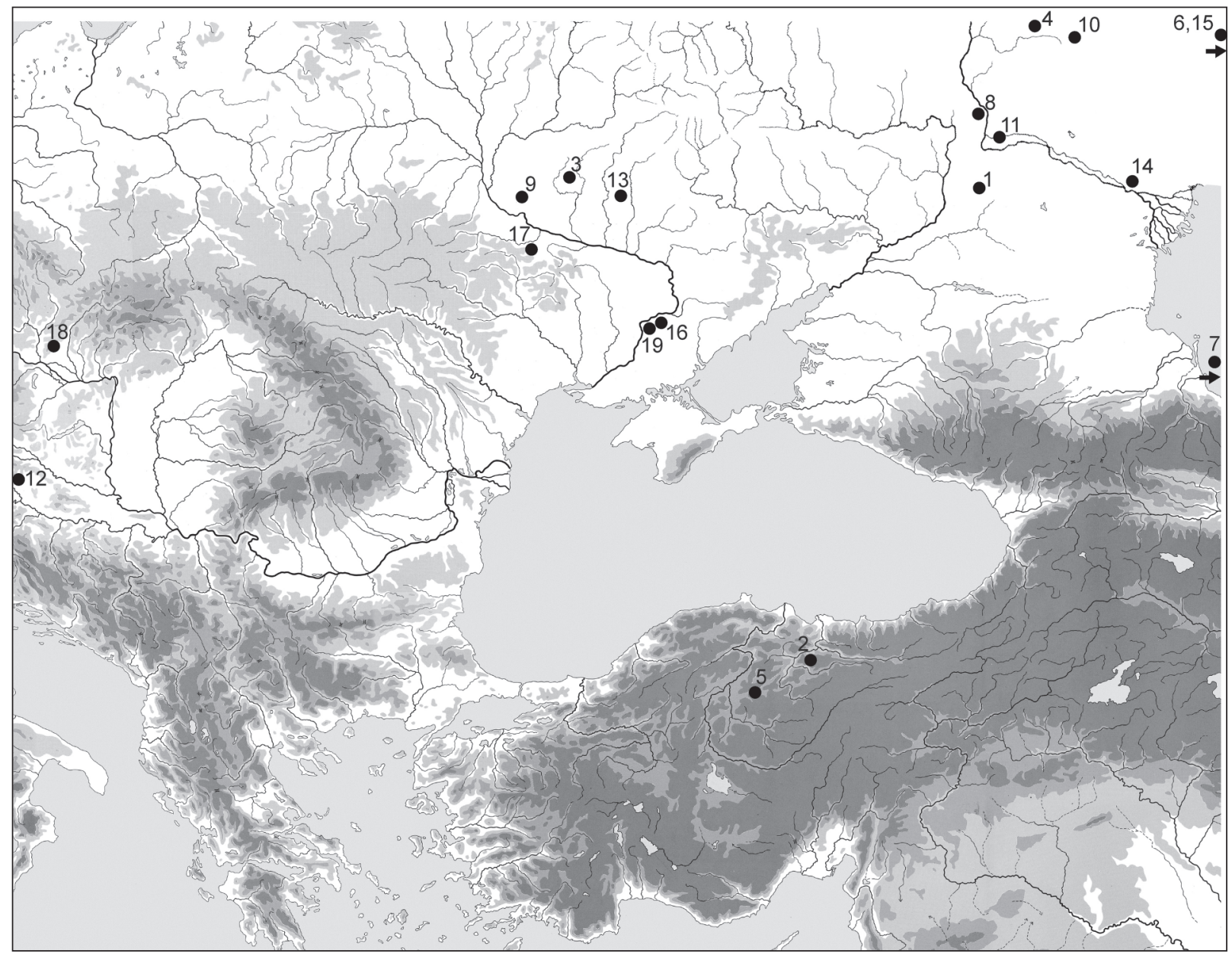

Abb. 3. Im Text genannte Fundorte, 1 - Aksjenovskij (Russland); 2 - Amasya bei Ladik (Türkei); 3 - Basovka (Ukraine); 4 - Blumenfeld' Kurgan (Russland); 5 - Boğazköy (Türkei); 6 - Gumarovo Kurgan (Russland); 7 - Issyk (Kasachstan); 8 - Kamyschin (Russland); 9 - Korniyvka (Ukraine); 10 - Lapasina (Russland); 11 - Leninsk (Russland); 12 - Libna (Slowenien); 13 - Lichačevka (Ukraine); 14 - Nižnjego Povolž’ja (Russland); 15 - Pjatmary (Russland); 16 - Pridneprovka (Ukraine); 17 - Repjahovataja Mogila (Ukraine); 18 - Smolenice-Molpír (Slowakei); 19 - Vysokaja Mogila (Ukraine). 
ortsansässigen Bevölkerung im Dorf Smolenice zufolge ${ }^{7}$ wurden besonders Pfeilspitzen während der Ausgrabungen Dušeks im Abraum aufgelesen und gelangten zahlreich in private Sammlungen. 753 bronzene Pfeilspitzen einer derartigen Sammlung konnten im Slowakischen Nationalmuseum/Archäologisches Museum in Bratislava zeichnerisch dokumentiert werden. ${ }^{8}$

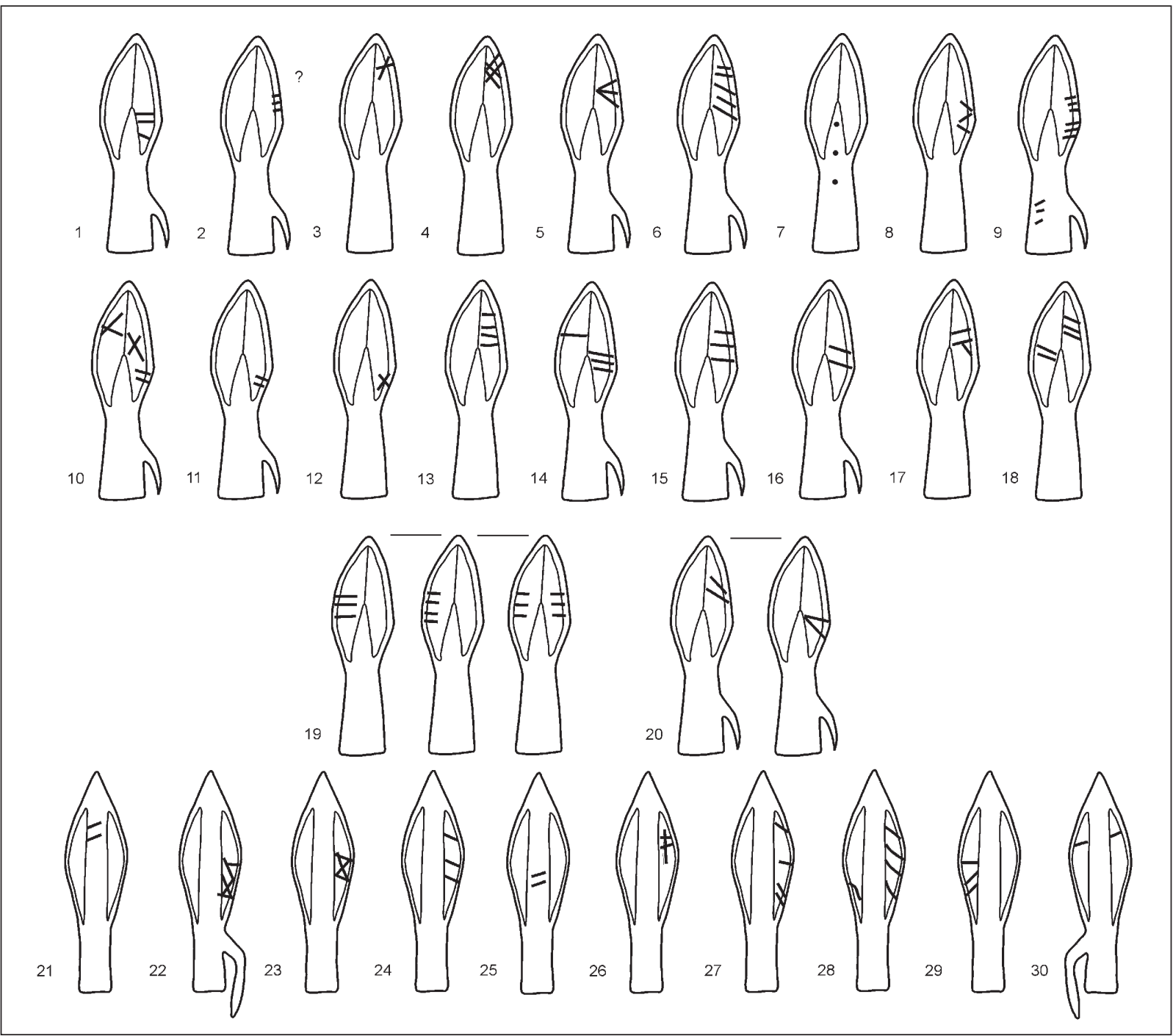

Abb. 4. Eingeritzte Zeichen auf Pfeilspitzen aus Smolenice-Molpír (unpubliziert), die im Slowakischen Nationalmuseum - Archäologisches Museum in Bratislava dokumentiert wurden.

1 - 131-SM 777; 2 - 153-SM 798; 3 - 158-SM 803; 4 - 170-SM 815; 5 - 5; 6 - 46; 7 - 203-SM 592; 8 - 215-SM 604; 9 - 404-29/99; 10 - 424-SM 250; 11 - 443-SM 491; 12 - 518-54/99; 13 - 530-4/2000; 14 - 539; 15 - 541; 16 - 612-18/99; 17 - 656-69/2005; 18 710; 19 - 721; 20 - 727-SM 459; 21 - 401-20/99; 22 - 438-SM 304; 23 - 470-SM 518; 24 - 471-SM 519; 25 - 474-SM 522; 26 - 477SM 525; 27 - 480-SM 528; 28 - 523-61/99; 29 - 524-62/99; 30 - 652-64/2005. Privat-Sammlung Smolenice-Molpír.

Unter den Pfeilspitzen der Sammlung finden sich sowohl bei den zwei- als auch bei den dreiflügeligen Exemplaren 30 Stücke, die eingeritzte Zeichen auf dem Blatt tragen ${ }^{9}$ (Abb. 4). An zwei Spitzen ist wiederum ein einzelnes eingeritztes Kreuz erkennbar, wobei es einmal im rechten oberen Blattbereich

7 Gespräche mit Anwohnern in Smolenice waren unter anderem im Rahmen einer Exkursion mit anschließendem Praktikum der Freien Universität Berlin mit S. Stegmann-Rajtár und B. Teržan im Jahr 2002 möglich.

8 Die zeichnerische Dokumentation erfolgte durch R. Čambal. Eine Publikation und Auswertung der Pfeilspitzen durch R. Čambal und A. Hellmuth Kramberger befindet sich in Vorbereitung.

9 Da sich die Gesamtpublikation der Fundstücke in Vorbereitung befindet und der Fokus des Beitrags auf den Zeichen selbst liegt, werden an dieser Stelle „Stellvertreter" für die Pfeilspitzen abgebildet (vgl. auch Abb. 2). Die verwendeten „Stellvertreter" geben Auskunft über die jeweilige Pfeilspitzengrundform, ergo ob es sich um ein zwei- oder ein dreiflügeliges Stück 
vorkommt (Abb. 4: 3), einmal im rechten unteren Blattbereich (Abb. 4: 12). Zwei Kreuze auf einer linken und rechten Blattseite finden sich in Kombination mit doppelten schrägen Ritzlinien im rechten unteren Blattbereich (Abb. 4: 10). Eine Ritzung in Form einer unvollständigen "Sanduhr" findet sich auf einer zweiflügeligen Spitze, wobei in diesem Fall der obere Abschluss der "Sanduhr" fehlt und oberhalb dieser zusätzlich ein Winkel angebracht ist (Abb. 4: 22). Ein vollständiges, leicht schräg ausgerichtetes, Sanduhrförmiges Ritzzeichen findet sich auf einer weiteren zweiflügeligen Pfeilspitze ohne Widerhaken (Abb. 4: 23). Ein nahezu identisches Ritzzeichen ist auf einer zweiflügeligen Pfeilspitze ohne Widerhaken aus dem anatolischen Fundort Boğazköy (Boehmer 1972, Taf. 30: 895) belegt (Abb. 5: 2). Ein einfacher eingeritzter Winkel erscheint auf einer dreiflügeligen Pfeilspitze aus der Sammlung aus Smolenice-Molpír auf der rechten Blattseite, während auf einem anderen Flügel des gleichen Stücks zwei schräg nach unten ausgerichtete Ritzlinien angebracht sind (Abb. 4: 20). Schräg nach unten gerichtete parallele Ritzlinien erscheinen sowohl auf der linken als auch auf der rechten Blattseite auf verschiedenen Höhen einzeln (Abb. 4: 27, 30), doppelt (Abb. 4: 11, 16, 20, 27, 29), dreifach (Abb. 4: 14, 15, 18, 24) und vierfach (Abb. 4: 28) sowie in mehreren Bündeln aus zwei oder drei parallelen Ritzlinien (Abb. 4: 6).

Seltener sind die Ritzlinien auf der linken oder rechten Blattseite schräg nach oben ausgerichtet, wobei sie in der Kombination mit zusätzlichen Ritzungen auftauchen (Abb. 4: 17, 18, 28, 30) oder wiederum Bündel bilden (Abb. 4: 9). Schräge parallele Ritzungen erscheinen bei den zweiflügeligen Pfeilspitzen auch auf dem Tüllenbereich in der Blattmitte (Abb. 4: 21, 25) sowie auf der Tülle selbst (Abb. 4: 9). Außer den schräg nach oben oder schräg nach unten gerichteten parallelen Ritzlinien finden sich ebensolche in horizontaler Position, wiederum einzeln (Abb. 4: 14), doppelt (Abb. 4: 1), dreifach (Abb. 4: 19), vierfach (Abb. 4: 13, 19) oder in Kombination mit schrägen Ritzlinien (Abb. 4: 1, 29) entweder auf der linken oder rechten Blattseite.

An weiteren Ritzzeichen sind die Folgenden zu nennen: eine vertikale Linie, die von zwei parallelen Ritzungen mittig durchkreuzt wird (Abb. 4: 26), ein Paar sich gegenständig überkreuzende Doppelritzlinien (Abb. 4: 4), eine „Vogelspur" (Abb. 4: 5), drei schräg angebrachte Ritzungen, die ein Zickzack bilden (Abb. 4: 8) und ein T-förmiger Winkel (Abb. 4: 17). Außer den eingeritzten Zeichen befinden sich auf einer dreiflügeligen Pfeilspitze im oberen Bereich der Schäftungstülle drei übereinander angebrachte punktartige Vertiefungen (Abb. 4: 7; Punzen?).

\section{Andere Fundorte}

Wie einleitend erwähnt, sind Ritzzeichen auf Pfeilspitzen vom sogenannten skythischen bzw. reiternomadischen Typ auch für zahlreiche andere Fundplätze belegt und wurden in den letzten Jahren von verschiedenen Autoren einer Betrachtung unterzogen. Speziell mit den anatolischen Pfeilspitzenfunden mit eingeritzten und eingekerbten Markierungen hat sich D. Yalçılı beschäftigt, wobei er in diesen, als eine mögliche Interpretation, die Zeichen einer Werkstatt sieht (Yalçıklı 2009, 188). ${ }^{10}$ Eine Zusammenstellung von Pfeilspitzen mit Ritzzeichen der Vor- und Frühskythischen Zeit im Nordpontischen Raum wurde von M. Daragan vorgenommen, wobei auch Funde aus den Nachbarräumen zum Vergleich herangezogen werden (Daragan 2015).

Den frühesten Nachweis in einem vorskythischen Kontext des 10.-9. Jh. v. Chr. dürften kurze parallele Kerben im mittleren Blattbereich auf der Schäftungstülle auf zwei zweiflügeligen Pfeilspitzen aus der Vysokaja Mogila, Grab 5 bilden (Daragan 2015, 130, Abb. 1: 10, 11; Terenozhkin 1976, Abb. 7: 6, 12). ${ }^{11}$ Insgesamt sind diese Markierungen jedoch nur bedingt mit den variantenreichen Ritzungen auf den frühskythischen zwei- und dreiflügeligen Pfeilspitzen des 8.-7. Jh. v. Chr. zu vergleichen. Breite parallele Einkerbungen, insbesondere im Bereich der Schäftungstülle, finden sich jedoch mehrfach unter den reiternomadischen Funden aus anatolischen Fundplätzen dokumentiert (Abb. 5: 1-3, 6-11). Zu nennen sind hier zweiflügelige Pfeilspitzen mit mandel- und rautenförmigem Blatt mit ein bis drei parallelen Kerben aus Boğazköy (Abb. 5: 3; Boehmer 1972, Taf. 30: 895) und besonders auf zahlreichen Exemplaren aus einem beraubten Grab, welches zwischen Taşova und Ladik bei Amasya entdeckt wurde (Abb. 5: 6-11; Ivantchik

mit oder ohne Widerhaken handelt. Die jeweilige Variante nach der Typengliederung von A. Hellmuth (2006) findet sich hier nicht repräsentiert. Die Position der Ritzzeichen entspricht derjenigen am Originalstück.

10 Yalçıklı behandelt in seinem Aufsatz auch Pfeilspitzen mit drei tief eingeschnittenen Kerben an der Blattkante im unteren Flügelbereich (Yalçıklı 2009, 185 ff., Abb. 3-5), eine Form der Markierung, die hier nicht untersucht wird, da sie an den Pfeilspitzen aus Smolenice-Molpír nicht vorkommt.

11 Ein Überblick zur Diskussion der Zeitstellung der Vysokaja Mogila findet sich u. a. bei Hellmuth 2010, 154 ff. 


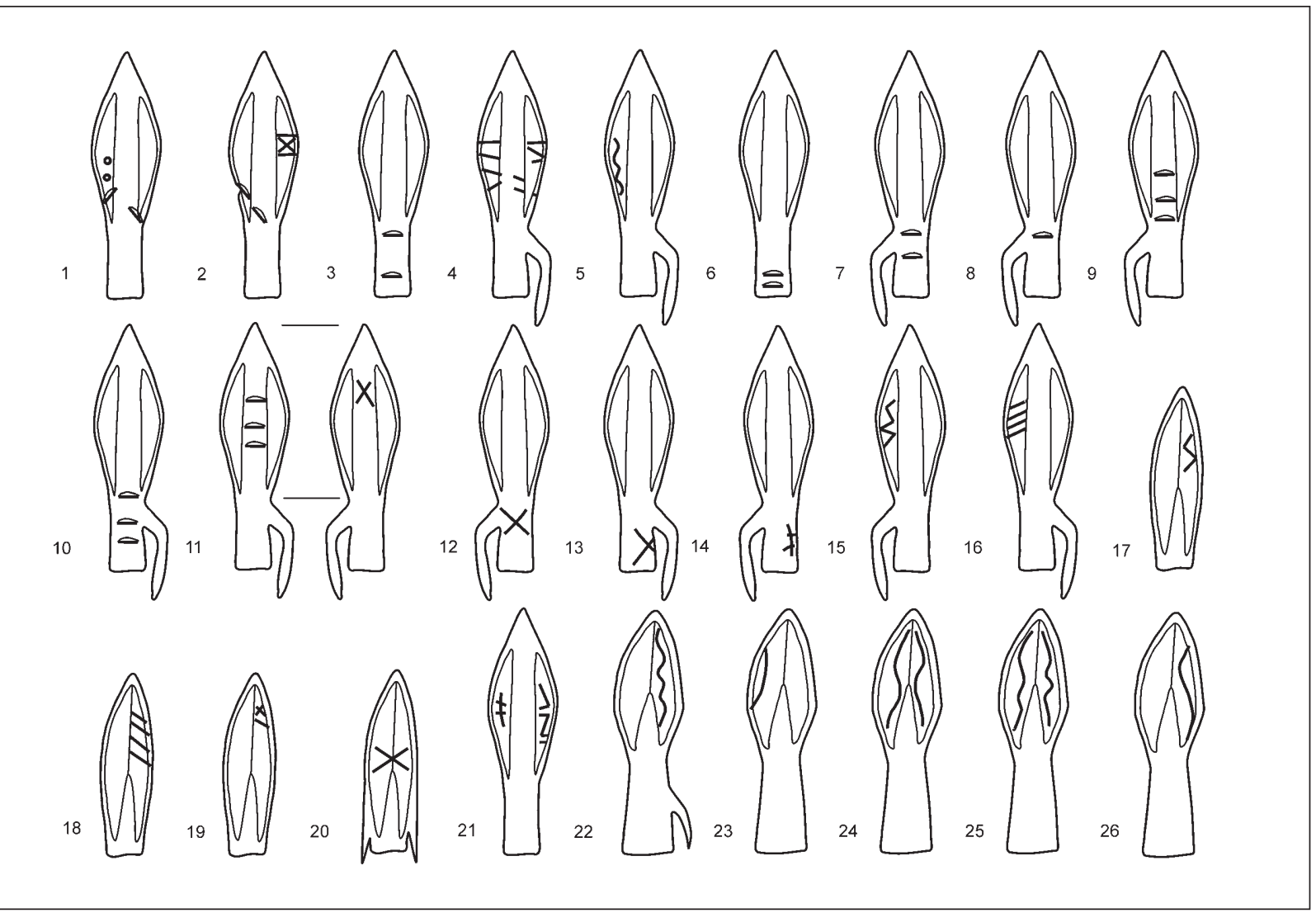

Abb. 5a. Zwei- und dreiflügelige Pfeilspitzen mit Ritzzeichen aus Anatolien, dem Unteren Wolgagebiet, Südlichem Uralvorland, Mittlerem Dneprgebiet, Siebenbürgen und dem Ostalpenraum.

1 - Boğazköy (Boehmer 1972, Taf. 30: 888); 2 - Boğazköy (Boehmer 1972, Taf. 30: 895); 3 - Boğazköy (Boehmer 1972, Taf. 30: 895); 4 - Boğazköy (Boehmer 1972, Taf. 31: 907); 5 - Boğazköy (Boehmer 1972, Taf. 31: 917); 6 - Amasya (Ivantchik 2001, Abb. 23: 10); 7 - Amasya (Ivantchik 2001, Abb. 23: 20, 21, 23, 24, 32-35, 38, 43-44, 48-55, 57-59, 61, 62, 67, 70-73, 75-78, 80-82, 84, 86, 87, 92-94, 133, 144, 147, 151, 161, 165, 166); 8 - Amasya (Ivantchik 2001, Abb. 23: 26, 83, 128, 152); 9 - Amasya (Ivantchik 2001, Abb. 23: 36, 134, 184); 10 - Amasya (Ivantchik 2001, Abb. 23: 228); 11 - Amasya (Ivantchik 2001, Abb. 23: 134); 12 - Amasya (Ivantchik 2001, Abb. 23: 202); 13 - Amasya (Ivantchik 2001, Abb. 23: 203); 14 - Amasya (Ivantchik 2001, Abb. 23: 204); 15 - Amasya (Ivantchik 2001, Abb. 23: 227); 16 - Tejuş (?), Museum Cluj (Hellmuth 2006, Taf. 22: 6); 17 - Basovka (Hellmuth 2010, Taf. 24: 18); 18 - Pridneprovka (Hellmuth 2010, Taf. 184: 2); 19 - Pridneprovka (Hellmuth 2010, Taf. 184: 4); 20 - Korniyvka (Полін 1987, Abb. 12: 26); 21 - Kamyschin (?; Rau 1929, Taf. 20: 1D); 22 - Nižnjego Povolž'ja (Hellmuth 2010, Taf. 148: 30); 23 - Aksjenovskij (Hellmuth 2010, Taf. 4: 15); 24 - Aksjenovskij (Hellmuth 2010, Taf. 4: 17; 5: 30; 8: 11; 11: 20, 21, 23); 25 - Aksjenovskij (Hellmuth 2010, Taf. 8: 9); 26 - Aksjenovskij (Hellmuth 2010, Taf. 4: 18, 19; 11: 54). Ritzzeichen auf Pfeilspitzen verschiedener Fundorte. Die dargestellten Pfeilspitzen sind „Stellvertreter“ für die jeweilige Grundform und repräsentieren nicht das Original.

2001, Abb. 23: 10, 20, 21, 23, 24, 26, 32-36, 38, 43, 44, 48-55, 57-59, 61, 62, 67, 70-73, 75-78, 80-84, 86, 87, 92-94, 128, 133, 134, 144, 147, 151, 152, 161, 165, 166, 184, 228). Unter den Pfeilspitzen aus Boğazköy sind auch Exemplare mit diagonalen Kerben im unteren Blattbereich zu nennen (Abb. 5: 1, 2; Boehmer 1972, Taf. 30: 888, 895). Sowohl in Boğazköy als auch beim Grabfund bei Amasya kommen die tiefen Kerben, wenn auch nicht besonders häufig, in Kombination mit feinen eingeritzten Zeichen vor. ${ }^{12} \mathrm{Zu}$ nennen sind ein sanduhrförmiges Zeichen bzw. ein Zeichen, das an die römische Ziffer X erinnert (Abb. 5: 2), sowie ein einfaches Kreuz (Abb. 5: 11). Ein einfaches Kreuz findet sich auch auf zwei weiteren Spitzen aus Amasya am äußeren Tüllenbereich zweier zweiflügeliger Pfeilspitzen mit Widerhaken (Abb. 5: 12, 13; Ivantchik 2001, Abb. 23: 202, 203). Weitere Ritzzeichen, die für anatolische Pfeilspitzenfunde genannt

\footnotetext{
12 Eine weitere Form der „Markierungen“, die auch bei den anatolischen Pfeilspitzenfunden vorkommen, sind gegossene Zeichen, die von A. Ivantchik als „Vogelspuren“ bezeichnet wurden (Ivantchik 2001, 55, Abb. 24). Die gegossenen Zeichen, die eine eigene Gruppe bilden, werden weiter unten behandelt. Für Anatolien (Gleiches gilt auch für die Ukraine) liegen auch aus dem Kunsthandel zahlreiche, besonders zweiflügelige, Pfeilspitzen mit Ritzzeichen und gegossenen Markierungen vor, wobei es wiederum um „Vogelspuren“, Punzen, parallele diagonale Linien und Winkel geht. Für einen Einblick und rege Diskussionen danken wir O. Sprenger.
} 
werden können, sind parallele diagonale Ritzlinien und Winkel (Abb. 5: 4; Boehmer 1972, Taf. 31: 907), eine einfache senkrechte Linie mit zwei horizontalen parallelen Einritzungen (Abb. 5: 14; Ivantchik 2001, Abb. 23: 204), eine schlangenförmige oder möglicherweise Reflexbogen-förmige (Abb. 5: 5; Boehmer 1972, Taf. 31: 917) sowie eine zickzackförmige Ritzung (Abb. 5: 15; Ivantchik 2001, Abb. 23: 227). Interessant ist eine doppelte Punktförmige, vermutlich punzierte, Markierung auf einer zweiflügeligen Pfeilspitze aus Boğazköy (Abb. 5: 1; Boehmer 1972, Taf. 30: 888) - an diese erinnert die dreifache Punktförmige Markierung auf der Schäftungstülle an einem Stück aus Smolenice-Molpír (Abb. 4: 7).

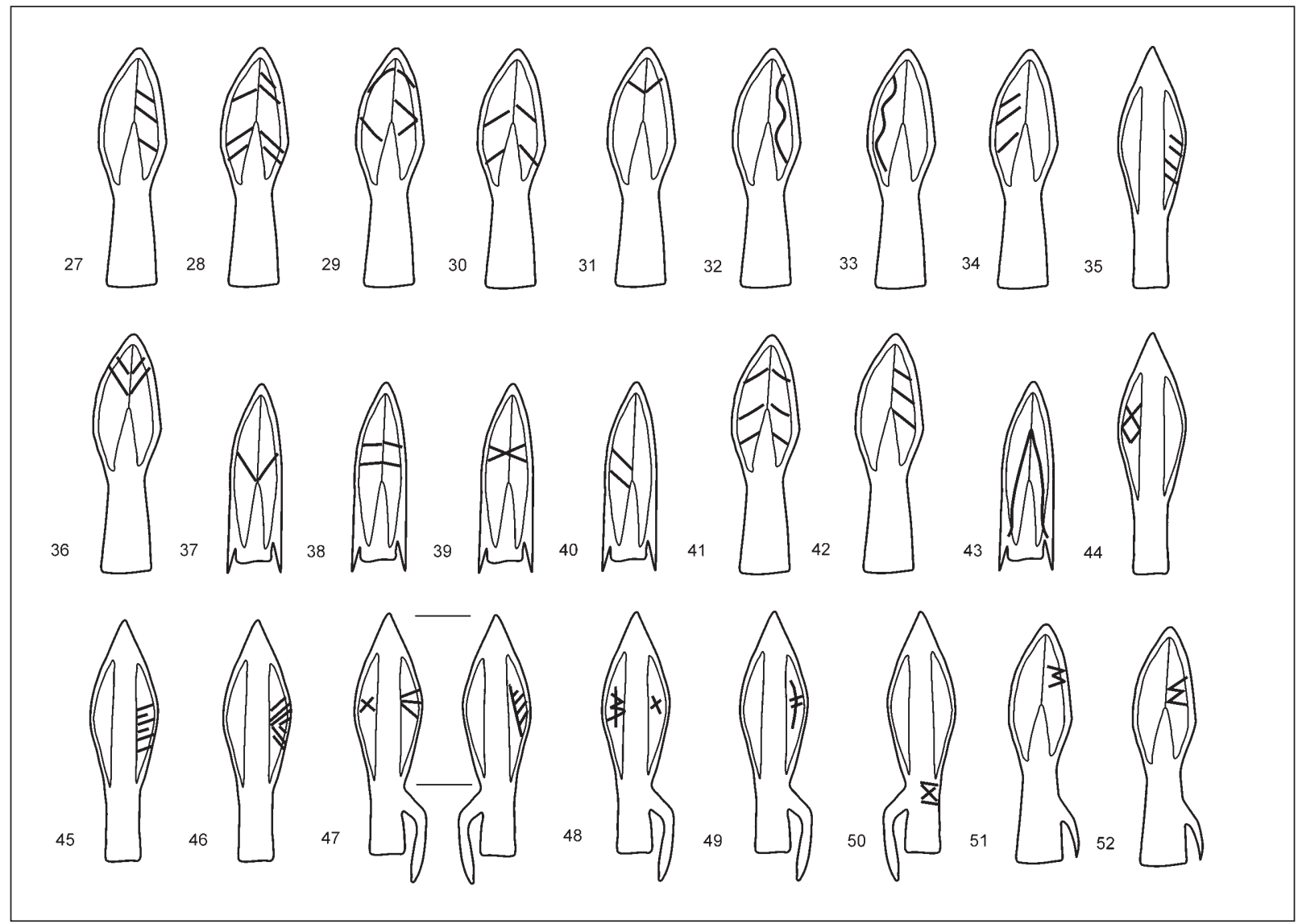

Abb. 5b. Zwei- und dreiflügelige Pfeilspitzen mit Ritzzeichen aus Anatolien, dem Unteren Wolgagebiet, Südlichem Uralvorland, Mittlerem Dneprgebiet, Siebenbürgen und dem Ostalpenraum.

27 - Aksjenovskij (Hellmuth 2010, Taf. 5: 32); 28 - Aksjenovskij (Hellmuth 2010, Taf. 8: 10); 29 - Aksjenovskij (Hellmuth 2010 , Taf. 8: 12); 30 - Aksjenovskij (Hellmuth 2010, Taf. 11: 24); 31 - Aksjenovskij (Hellmuth 2010, Taf. 11: 53 ); 32 - Blumenfeld“ (Hellmuth 2010, Taf. 38: 13); 33 - Blumenfeld' (Hellmuth 2010, Taf. 38: 14, 16); 34 - Blumenfeld' (Hellmuth 2010, Taf. 38: 15); 35 - Pjatimari (Смирнов 1964, Abb. 26: 1); 36 - Pjatimari (Смирнов 1964, Abb. 44: 1 zweite Reihe, 7. von rechts); 37-39 - Süd-Ural, eingeritzt oder gegossen? (Смирнов 1964, Abb. 37: 17-19; 39: 8); 40 - Lapasina, eingeritzt oder gegossen? (Смирнов 1964, Abb. 43: 2); 41 - Leninsk (Смирнов 1964, Abb. 52: 7); 42 - Leninsk (Смирнов 1964, Abb. 52 : 18); 43 - Libna (Hellmuth 2007); 44 - Gumarovo (Дараган 2015, Abb. 6: 1); 45 - Gumarovo (Дараган 2015, Abb. 7: 17); 46 - Gumarovo (Дараган 2015, Abb. 7: 18); 47 - Glinišče (Дараган 2015, Abb. 9: 32); 48 - Glinišče (Дараган 2015, Abb. 9: 33); 50 - Povolž je (Дараган 2015, Abb. 9: 29); 5 - Žabotin, Siedlung (Дараган 2015, Abb. 11: 11); 52 - Žabotin, Siedlung (Дараган 2015, Abb. 11: 15). Ritzzeichen auf Pfeilspitzen verschiedener Fundorte. Die dargestellten Pfeilspitzen sind "Stellvertreter" für die jeweilige Grundform und repräsentieren nicht das Original.

Generell kann festgestellt werden, dass sich für nahezu jedes Ritzzeichen an den Pfeilspitzen aus Smolenice-Molpír Vergleiche zu Pfeilspitzen aus Anatolien einerseits sowie dem Nordpontischen Raum andererseits finden lassen. Einzelne und mehrere parallele Ritzlinien, die horizontal (Abb. 4: 13-15, 19), diagonal nach außen oben (Abb. 4: 2, 9, 21, 25) oder außen unten (Abb. 4: 6, 10, 11, 16, 20, 24) sowie in unterschiedlicher Kombination (Abb. 4: 1, 18, 27-30) angeordnet sein können, stellen dabei die häufigsten Vertreter dar und erscheinen sowohl an den zwei- als auch an dreiflügeligen Pfeilspitzentypen. Für den östlichen Steppenraum können vor allem Pfeilspitzenfunde aus dem Unteren Wolga- und Südlichen 
Uralgebiet benannt werden. So beispielsweise den Kurgan-Nekropolen bei Aksjenovskij (Shilov/OchirGorjeva 1997; vgl. Hellmuth 2010, 91 f., Taf. 4; 5; 8; 11) zwischen Unterer Wolga und Don (Abb. 5: 27, 28, 30), dem ebenfalls im Einzugsgebiet der Wolga gelegenen sogenannten Blumenfeld' Kurgan A12 (Abb. 5: 34; Smyrnov 1964; vgl. Hellmuth 2010, Taf. 38) sowie aus verschiedenen Kurgan-Nekropolen im südlichen Uralvorland (Abb. 5: 35-37, 45; Daragan 2015, Abb. 6: 2, 9; 7: 17, 19; Hellmuth 2010, 91; Ismagilov 1988; Smyrnov 1964, Abb. 26: 1; 37: 17, 18; 44: 1; 43: 2; 52: 7, 18). Für das ukrainische Mittlere Dneprgebiet kann zum Beispiel auf Funde aus den Köchern in Grab 1 und 2 der Repjahovataja Mogila (Il'ienskajal Mozopevskij/Terenozhkin 1980; Daragan 2015, Abb. 13: 19; 14: 15-18) oder einem Kurgan bei Lichačevka (Daragan 2015, Abb. 10: 17-20, 22, 23) verwiesen werden. Mehrfach kommt auf den Pfeilspitzen aus Smolenice-Molpír ein eingeritztes Kreuz vor, wobei dies einfach (Abb. 1: rechts unten; 2: links oben; 4: 3, 12) oder doppelt (Abb. 4: 10) im Bereich des Blattes angebracht sein kann. Unter den anatolischen Funden erscheint das eingeritzte Kreuz auch im äußeren Schäftungstüllen-Bereich (Abb. 5a: 12, 13; Ivantchik 2001, Abb. 23: 202, 203). In einem Fall ist das Kreuz sowohl im oberen, als auch im unteren Bereich durch eine horizontale Einritzung "geschlossen“ und ergibt damit die Form einer Sanduhr (Abb. 4: 23). Auch für dieses Zeichen finden sich Entsprechungen sowohl in Anatolien, in Boğazköy (Abb. 5a: 2; Boehmer 1972, Taf. 30: 895), als auch im Nordpontischen Raum (Abb. 5b: 50; Daragan 2015, Abb. 9: 29). Seltener sind in Smolenice andere Zeichen wie ein einfacher (Abb. 2, rechts; 4: 20) oder doppelter Winkel (Abb. 2: Mitte), eine „Vogelspur“ (Abb. 4: 5) oder Zickzack (Abb. 4: 8) vertreten. Eine Form der Einritzung, die bislang in Smolenice-Molpír nicht dokumentiert ist, stellen die Schlangenlinien bzw. ein „Reflexbogen“ dar (vgl. Abb. 5a: 5, 22, 24-26; 5b: 32, 33). An diese erinnert jedoch eine feine 
spitzbogenförmige Ritzung an einer dreiflügeligen Pfeilspitze mit innerer Schäftungstülle aus dem sog. Bogenschützengrab von Libna in Slowenien (Abb. 5b: 43; Hellmuth 2007, 467, Abb. 1: 55).

\section{PFEILSPITZEN MIT GEGOSSENEN ZEICHEN}

Eine ganze Reihe an Zeichen, die in eingeritzter Form ${ }^{13}$ in Smolenice-Molpír sowie den oben genannten Fundplätzen zwischen Mittlerem Dnepr, Unterer Wolga, südlichem Uralvorland und Anatolien vorkommt, findet sich auch als gegossene Zeichen (Abb. 6). Genannt werden können wiederum horizontale oder diagonale Linien bzw. Linienbündel (Abb. 6: 6, 8, 11, 12, 14, 16, 20-22, 24), Kreuze (Abb. 6: 13, 15, 23) oder eine Kombination aus beidem (Abb. 6: 19). Eine spezielle Gruppe bilden die bereits genannten „Vogelspuren“, wie sie beispielsweise auf Pfeilspitzen aus Boğazköy (Boehmer 1972, Taf. 31: 902) als auch im Grabfund bei Amasya (Ivantchik 2001, Abb. 24: 5-7) oder im Grab 3 im Kurgan 1 von Gumarovo (Daragan 2015, 138, Abb. 6: 6, 8, 15; Ismagilov 1988; Ivantchik 2001, 55, Abb. 24: 1-3) im südlichen Uralvorland dokumentiert sind (Abb. 6: 1, 2).

Es fällt auf, dass gegossene Zeichen wie die „Vogelspuren“ vor allem an zweiflügeligen Pfeilspitzen des 8.-7. Jh. v. Chr. vorkommen, während alle übrigen Formen in der Regel an dreiflügeligen Pfeilspitzen mit innerer Tülle zu registrieren sind. Letztere repräsentieren dabei die allgemein jüngeren Pfeilspitzenformen der Klassischen Skythenzeit ab der zweiten Hälfe des 6. Jh. v. Chr. ${ }^{14}$

\section{ZUSAMMENFASSUNG UND INTERPRETATIONSANSATZ}

Zusammenfassend können wir feststellen, dass sich die eingeritzten Zeichen auf den sogenannten skythischen Pfeilspitzen aus Smolenice-Molpír sowie dem Nordpontischen Raum und Anatolien nach dem derzeitigen Forschungs- und Publikationsstand grob in 14 verschiedene Gruppen einteilen lassen (Abb. 7).

Die erste Gruppe (a) bilden Einkerbungen, die überwiegend horizontal, seltener diagonal angebracht wurden und meist im Bereich der Schäftungstülle sitzen. Es handelt sich um eine Markierung, die zwar in Smolenice nicht registriert ist, aber dennoch in Kombination mit Ritzzeichen vorkommt, die wir ebenfalls hier finden und für die sich ein gewisser Schwerpunkt in der Verbreitung in Anatolien bemerken lässt. Keine eigentliche Gruppe, da bisher nur in wenigen Beispielen vertreten, stellen Punktartige Markierungen (b) dar. Parallele Ritzlinien können in sechs Haupt-Gruppen gegliedert werden (c-h) und stellen die am häufigsten vertretenen Einritzungen dar, die teilweise auch in Kombination mit anderen Zeichen vorkommen. Unterschieden werden kann zwischen horizontalen und diagonalen Einritzungen, die entweder nur auf einer oder beiden bzw. mehreren Flügelseiten angebracht sind. Die Gruppe c zeigt dabei horizontale Einritzungen, die nur auf einer Flügelseite erscheinen und meist eine bis vier, selten mehr, parallele Ritzlinien umfassen. Derartige parallele horizontale Einritzungen finden sich auch in Gruppe d, kommen hier jedoch auf zwei Flügelseiten vor, wobei sie rechts und links von der Mittelrippe/ der Schäftungstülle angeordnet, eine Einheit zu bilden scheinen. Eine bis vier, selten mehr, diagonale parallele Ritzlinien, die nach außen oben weisen, bilden eine weitere Gruppe (e). Auch diese nach außen und oben weisenden parallelen Ritzungen kommen in der Anordnung auf zwei Flügelseiten vor (f). Beide Varianten erscheinen auch mit diagonalen parallelen Ritzlinien, die nach außen unten ausgerichtet sind $(\mathrm{g}, \mathrm{h})$. Verschiedene Varianten umfasst die Gruppe an Ritzzeichen, die auf einem Kreuz aufbauen (i, j). Das Kreuzmotiv erscheint dabei im gesamten Verbreitungsgebiet am häufigsten in einfacher Form auf dem Pfeilspitzenblatt sowie auch auf der Schäftungstülle. Seltener ist das Kreuz im oberen oder unteren Bereich mit einer zusätzlichen Linie versehen oder kommt in einer doppelten, sich überschneidenden Ausführung vor (j). Eine weitere Gruppe umfassen winkelförmige Einritzungen (k) unter denen die wohl markanteste Variante die „Vogelspur" bildet. Insbesondere bei letzterer handelt es sich um eine Form, die häufig auch in gegossener Form an zweiflügeligen Pfeilspitzen vorkommt. Nahe verwandt zur Gruppe k sind Doppelwinkel (l). Eher selten scheinen zickzackförmige Einritzungen (m) zu sein. Interes-

\footnotetext{
13 Da gegossene Zeichen in Smolenice-Molpír nicht vorkommen, wird die Thematik im Folgenden nur gestreift. Eine ausführliche Behandlung erfordert eine gesonderte Studie.

14 Zur Chronologiediskussion vgl. Hellmuth 2010, 154 ff., Synthese $323 \mathrm{ff}$.
} 
sant, da von allen anderen linearen Einritzungen abweichend, sind schlangenlinienförmige Zeichen (o), die einen gewissen Verbreitungsschwerpunkt im Unteren Wolgagebiet aufzuweisen scheinen. Zeichen der Gruppe o weichen nicht nur auf Grund ihrer kurvolinearen Formgebung von allen Übrigen ab, sie scheinen auch einen konkreten Gegenstand darzustellen - möglicherweise einen stilisierten Reflexbogen. Unter der letzten Gruppe (n) finden sich verschiedene Ritzungen, deren gemeinsames Merkmal eine gerade oder leicht gekrümmte vertikale Linie bildet.

Abschließend stellt sich nun die Frage, wie die markanten Zeichen auf den Pfeilspitzen vom sogenannten skythischen bzw. reiternomadischen Typ zu bewerten sind? Sicherlich bleibt eine Ansprache als "Schrift" ohne eine linguistische Untersuchung spekulativ und kann auch hier nicht erfolgen, doch haben die hier aufgeführten Vergleiche gezeigt, dass wir es mit einem wiederkehrenden, durchaus komplexen und im gesamten reiternomadischen Kulturkreis verbreiteten Zeichensystem zu tun haben. ${ }^{15}$ Zwar zählt der reiternomadische Kulturkreis (bis dato) insgesamt $\mathrm{zu}$ den schriftlosen Kulturen der Eisenzeit, doch hatten seine Träger bewiesenermaßen intensive Kontakte zu verschiedenen benachbarten Kulturkreisen, die über eine Schriftkultur verfügten. In erster Linie wäre hier $a b$ dem späten 8. und im 7. Jh. v. Chr. an Kontakte mit Assyrern, Phrygern und Griechen zu denken. Dabei lassen sich einzelne Zeichen durchaus in der alt-griechischen Alphabetschrift (z. B. Haarmann 1998, 282 ff., 287 ff., Abb. 167) wiederfinden, wie beispielsweise $\Psi$ (psi; vgl. Abb. 7: k), X (chi; vgl. Abb. 7: i), ฯ (üpsilon; vgl. Abb. 7: k), T (tau; vgl. Abb. 7: n), $\Sigma$ (sigma; vgl. Abb. 7: m, l), M (mü; vgl. Abb. 7: 1) oder $\Lambda$ (lambda; vgl. Abb. 7: k), doch stellen sie nur einen vergleichsweise geringen Anteil dar. Bei den benannten Zeichen handelt es sich um solche, die sich in der (Jüngeren) Eisenzeit auch unter den „alpinen“ Schriften des etruskischen Schriftkulturkreises finden (Abb. 8; Haarmann 1998, 455 ff., Abb. 318).

Von Interesse ist zweifellos auch der bemerkenswerte und unikate Fund einer Silberschale mit Inschrift, die im Kurgan von Issyk im heutigen Kasachstan zutage kam (Abb. 9; Rolle 1980, 51, Abb. unten rechts; Samashev 2007, 167, Abb. 13). ${ }^{16}$ Die Entzifferung dieser oftmals als "runenartig“ angesprochenen Inschrift ist nach wie vor umstritten (z. B. Amanjolov 1971; Samashev 2007, 167). Vergleichbar mit den Ritzungen auf den Pfeilspitzen sind auch hier wieder nur einzelne Zeichen, die wiederum

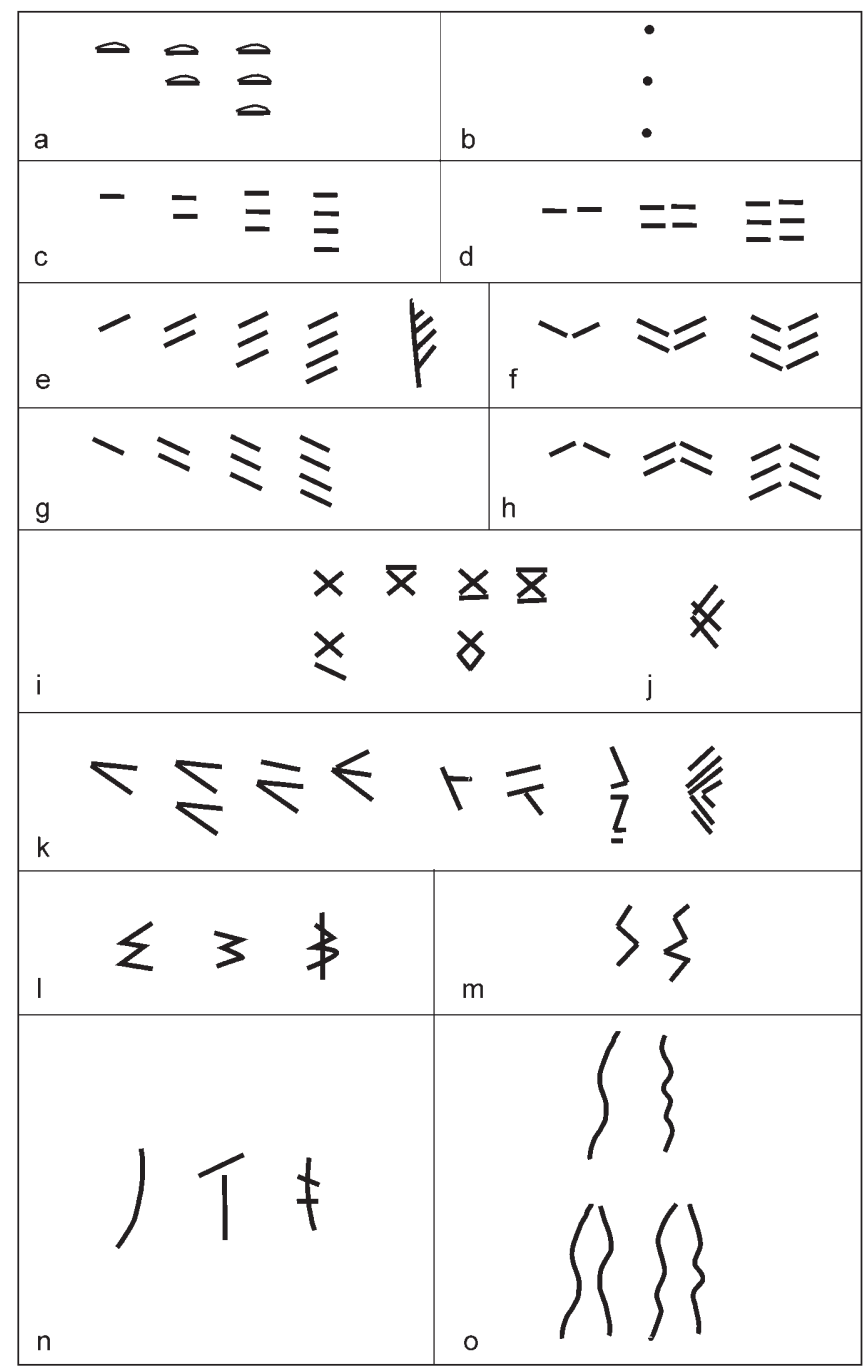

Abb. 7. Die verschiedenen Gruppen von Ritzzeichen auf den zwei- und dreiflügeligen Pfeilspitzen vom sogenannten skythischen oder reiternomadischen Typ im gesamten Gebiet ihrer Verbreitung. $\mathrm{a}$ - Kerben; $\mathrm{b}$ - Punzen; $\mathrm{c}$ - (parallele) horizontale Linien auf einer Flügelseite; $d$ - (parallele) horizontale Linien auf beiden Flügelseiten; e - (parallele) diagonale, nach oben gerichtete Linien auf einer Flügelseite; $\mathrm{f}$ - (parallele) diagonale, nach oben gerichtete Linien auf beiden Flügelseiten; g - (parallele) diagonale, nach unten gerichtete Linien auf einer Flügelseite; $\mathrm{h}$ - (parallele) diagonale, nach unten gerichtete Linien auf beiden Flügelseiten; i, j - Kreuze; k - Winkel; 1 - Doppelwinkel; m - Zickzack; n - senkrechte Linien; o - Schlangenlinien/„Reflexbogen".

15 Die relativ große Anzahl an Zeichen lässt dabei weniger an eine phonographische Schrift denken als vielmehr an eine Logographie.

16 Kurgan von Issyk: Akishev 1978 - Der Kurgan von Issyk wurde insbesondere durch seine reiche unberaubte Nebenbestattung bekannt, die sich häufig als "Goldener Mann von Issyk" betitelt findet. 
EINE SCHRIFT DER REITERNOMADEN IM 1. JT. V. CHR.?

\begin{tabular}{|c|c|c|c|c|c|c|}
\hline & \multicolumn{3}{|c|}{ Rätische Alphabete } & \multirow{2}{*}{ Lepontisch } & \multirow{2}{*}{ Venetisch } & \multirow{2}{*}{$\mid \begin{array}{c}\text { Etruskisches } \\
\text { Vorbild }\end{array}$} \\
\hline & Bozen & Magrè & Sandria & & & \\
\hline a & $\wedge \wedge A \wedge A$ & $\Delta \forall A$ & $\lambda \lambda \hat{A}$ & $17 \wedge A \Delta$ & $49 \lambda$ & $A A$ \\
\hline e & 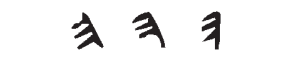 & 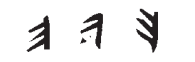 & 丰 7 & 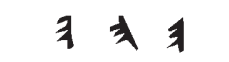 & 习 & $1 y$ \\
\hline $\mathrm{v}$ & 1777 & 79 & & & 7 & 71 \\
\hline z & & $\neq ?$ & 木全 & $\neq$ & $x x$ & $\neq \pm I$ \\
\hline $\mathrm{h}$ & A & | $\mid$ & & & 小百 & 日日 \\
\hline th & $\beta$ & $B B$ & $\because \quad 2$ & & $\odot \otimes$ & $\odot 8$ \\
\hline i & 1 & 1 & 1 & 1 & 1 & I \\
\hline k & $y \quad x$ & $x \neq \lambda$ & 자 & $\forall x$ & $y$ & כ \\
\hline 1 & $\checkmark$ & 1 & $\uparrow$ & $\checkmark$ & 1 & $\checkmark$ \\
\hline $\mathrm{m}$ & $M$ & $M x$ & $W ?$ & myung & $m$ & $M M$ \\
\hline $\mathrm{n}$ & 4 & $Y \sim n$ & $N n^{2}$ & $444 n$ & 4 & $4 \pi$ \\
\hline o & & & $0 ?$ & $0 \cap 0 \diamond 9$ & 0 & \\
\hline$p$ & $\uparrow 1 \uparrow$ & & 1 & 1 & 1 & 11 \\
\hline š & M & $M M$ & $\bowtie$ & $\bowtie M X M$ & M & $M M$ \\
\hline r & $\triangle 0$ & 4440 & & $\triangle 0 d$ & 40 & 0 \\
\hline $\mathrm{s}$ & $x<<$ & $23 x$ & 2 & $\sum_{s} \sum_{2} s$ & 23 & $3<42$ \\
\hline $\mathrm{t}$ & $x \times x$ & $x x+$ & $x$ & $x \quad x$ & $\times \uparrow$ & けヤイ \\
\hline u & $V$ & $\wedge V$ & $\wedge \wedge ?$ & $\checkmark / Y Y$ & $\wedge$ & $V Y Y$ \\
\hline $\mathrm{ph}$ & $\phi q \diamond ?$ & $ه \diamond \phi$ & & $\triangleright ?$ & (1) (1) 6? & $\phi$ \\
\hline $\mathrm{kh}$ & $Y \vee \uparrow$ & $Y$ & & $Y \quad \vee$ & $Y g ?$ & $Y v$ \\
\hline ĭi,e & & & & $11 ?$ & II & \\
\hline p & & 88 & & & & \\
\hline
\end{tabular}

Abb. 8. „Alpine“ Schriften des etruskischen Schriftkulturkreises in der Jüngeren Eisenzeit (reproduziert nach Haarmann 1998). 


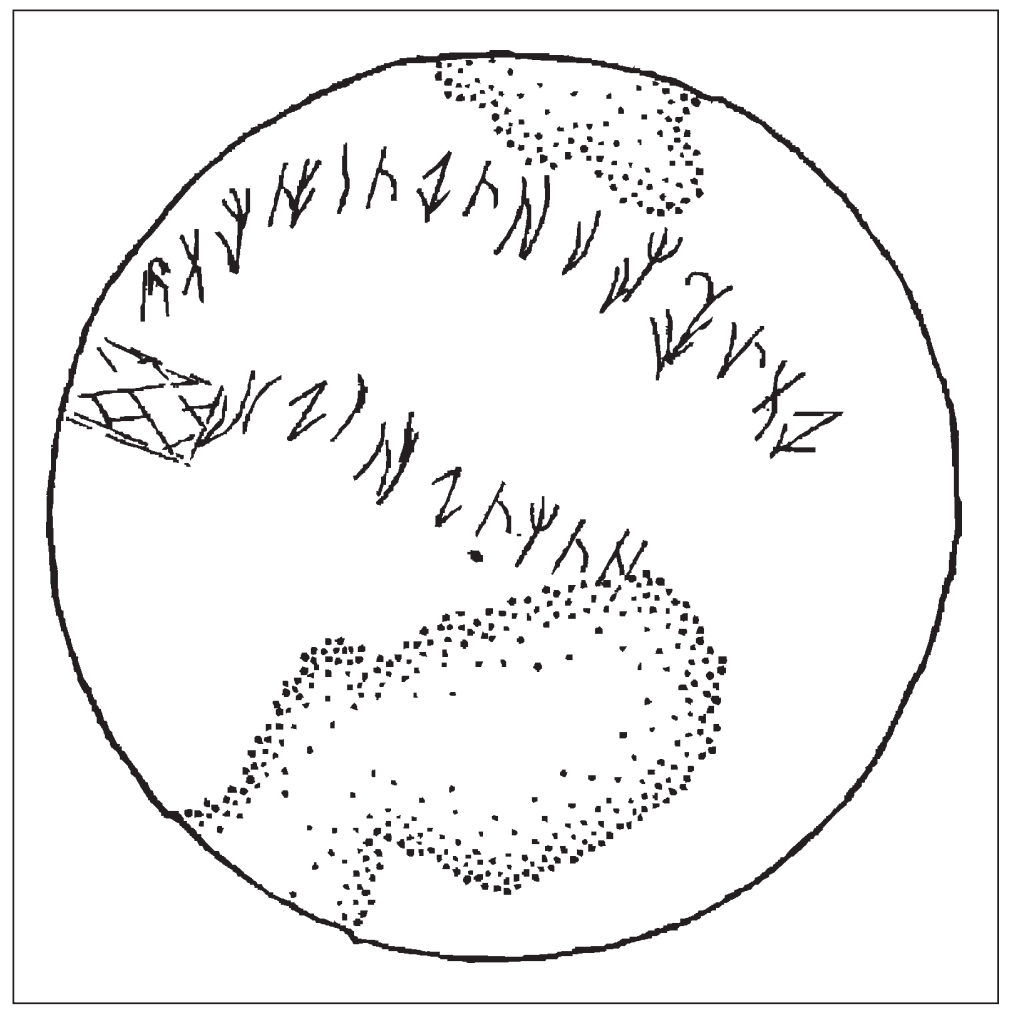

Abb. 9. Umzeichnung der Inschrift auf der Silberschale aus dem Kurgan von Issyk, Kasachstan (reproduziert nach Samašev 2007).

an Buchstaben des Alt-Griechischen wie $\Sigma$ (sigma), $\Lambda$ (lambda) oder X (chi) errinnern.

Es mag von Bedeutung sein, dass insgesamt unter den Ritzzeichen auf den Pfeilspitzen Kombinationen aus horizontalen und diagonalen Linien dominieren (vgl. Abb. 7: c-h). Ihre Anordnung einseitig oder beidseitig der Mittelrippe bzw. Schäftungstülle könnte dabei entscheidend für die Lesung der einzelnen Zeichen sein. Eine Schrift, bei welcher Zeichen von einer Mittellinie ausgehen oder diese kreuzen, ist zum Beispiel die irische Ogham-Schrift, deren älteste Zeugnisse in das 4. Jh. zurück reichen, wobei ihre Entstehungszeit und Entwicklung unbekannt sind (Abb. 10; Haarmann 1998, 467 ff., Abb. 328). Bemerkenswerter Weise geht es auch hier um einzelne oder mehrfache horizontale oder diagonale (nach oben oder unten ausgerichtete) Linien und Punkte. Ob es sich jedoch bei den Ritzzeichen auf den sogenannten skythischen Pfeilspitzen um ein ähnliches Schriftsystem wie beim Ogham handelt, müssen zukünftige Studien an einer größeren Materialbasis beleuchten.

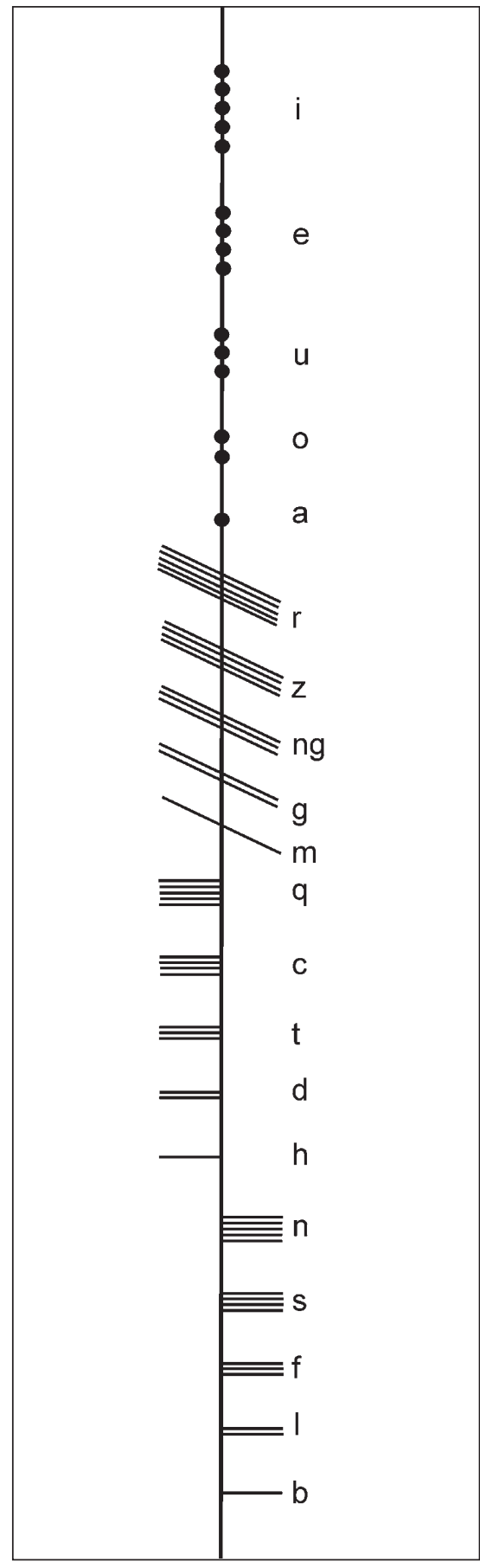

Abb. 10. Irische Ogham-Schrift (reproduziert nach Haarmann 1998). 


\section{LITERATUR}

Akishev 1978

Alekseev 1992

Amanjolov 1971

Boehmer 1972

Daragan 2015

Dušek 1974

Dušek, M./Dušek, S. 1984

Dušek, M./Dušek, S. 1995

Dvornichenko/Plachov/Ochir-Gorjaeva 1997

K. A. Akishev: Kurgan Issyk. Moskva 1978.

A. Yu. Alekseev: Skifskaya chronika. Skify v VII-V vv. do n. z.: istoriko-arkheologicheskii ocherk. Sankt Peterburg 1992.

A. Amanjolov: Runic-like inscription from Saka's burial near Alma-Ata. Bulletin of Academy of Sciences Kazakh SSR 12/320, 1971, 64-66.

R. M. Boehmer: Die Kleinfunde von Boğazköy, Boğazköy. Hattuša VII. Berlin 1972.

M. N. Daragan: Nakonechniki stel predskifskogo I ranneskifskogo vrepeni.

Technologija izgotovlenija, metrologija i markirovka. Trudui Gocydarstvennogo Ermitazha 77, 2015, 127-169.

M. Dušek: Der hallstattzeitliche Fürstensitz auf dem Molpír bei Smolenice. In: Symposium zu Problemen der Jüngeren Hallstattzeit. Bratislava 1974, 137-149.

M. Dušek/S. Dušek: Smolenice-Molpir - Befestigter Fürstensitz der Hallstattzeit I. Materialia Archaeologica Slovaca 6. Nitra 1984.

M. Dušek/S. Dušek: Smolenice-Molpír - Befestigter Fürstensitz der Hallstattzeit II. Materialia Archaeologica Slovaca 13. Nitra 1995.

V. V. Dvornichenko/V. V. Plachov/M. A. Ochir-Gorjaeva: Pogrebenija rannikh kokhevnikov ie Nizhnjego Povolzhja. Rossijskaja Archeologija 2, 1997, 127-141.

Eckhardt 1991

Galanina 1997

Haarmann 1998

Hellmuth 2006

Hellmuth 2007

Hellmuth 2010

Hellmuth Kramberger 2017

Il'ienskaja/Terenozhkin 1983

Il'ienskaja/Mozolevskij/Terenozhkin 1980

Ismagilov 1988

Ivantchik 2001

Lifantij 2011

Ludwig/Stegmann-Rajtár/Tirpák 2010

Müller 2012

Parzinger/Stegmann-Rajtár 1988

Polin 1987
H. Eckhardt: Der schwirrende Tod - die Bogenwaffe der Skythen. In: R. Rolle/M. Müller-Wille/K. Schietzel (Hrsg.): Gold der Steppe. Archäologie der Ukraine. Schleswig 1991, 143-149.

L. K. Galanina: Skifskie dronosti podierav'ja. Moskva 1977.

H. Haarmann: Universalgeschichte der Schrift. Frankfurt am Mein - New York 1998.

A. Hellmuth: Untersuchungen zu den sogenannten skythischen Pfeilspitzen aus der befestigten Höhensiedlung von Smolenice-Molpír. Universitätsforschungen zur prähistorischen Archäologie 128. Bonn 2006.

A. Hellmuth: Neues zum „Bogenschützengrab“ aus Libna. In: M. Blečić/M. Črešnar/B. Hänsel/A. Hellmuth/E. Kaiser/C. Metzner-Nebelsick (Hrsg.): Scripta praehistorica in honorem Biba Teržan. Situla 44. Ljubljana 2007, 465-475.

A. Hellmuth: Bogenschützen des Pontischen Raumes in der Älteren Eisenzeit. Typologische Gliederung, Verbreitung und Chronologie der skythischen Pfeilspitzen. Universitätsforschungen zur prähistorischen Archäologie 177. Bonn 2010.

A. Hellmuth Kramberger: Archäologische Hinweise zu kriegerischen Auseinandersetzungen mit reiternomadischen Gruppen im östlichen Mitteleuropa und im Vorderen Orient. In: E. Miroššayová/C. Pare/S. Stegmann-Rajtár (Hrsg.): Das Nördliche Karpatenbecken in der Hallstattzeit. Wirtschaft, Handel und Kommunikation in früheisenzeitlichen Gesellschaften zwischen Ostalpen und Westpannonien. Archaeolingua 38. Budapest 2017, 571-590.

B. A. Il'ienskaja/A. I. Terenozhkin: Skifija VII-IV vv. Do n. e. Kijiv 1983.

B. A. Il'ienskaja/Y. N. Mozolevskij/A. I. Terenozhkin: Kurgan'i VI v. do. n. e. u. s. Matusov. In: A. I. Terenozhkin (red.): Skifija i Kavkaz. Kijiv 1980, 31-63.

P. G. Ismagilov: Pogrebenie Golshogo Gumarovskogo kurgana v juzhnom Priural'e i problema proischozhdenija skifskoj kul'tur'i. Archeologicheskij sbornik gosudarstvennogo Ermitazha. E 29, 1988, 29-47.

A. I. Ivantchik: Kimmerier und Skythen. Kulturhistorische und chronologische Probleme der Archäologie der osteuropäischen Steppen und Kaukasiens in vor- und frühskythischer Zeit. Steppenvölker Eurasiens II. Moskva 2001.

O. V. Lifantij: Istorija vyvchennja mitok na bronzovych nakonecheykach stril skifs'koji dobe. Magisterium. Vypusk 45. Archeolohi'ni studiji 2011, 46-50.

K. Ludwig/S. Stegmann-Rajtár/J. Tirpák: Geofyzikálna prospekcia a obnovený systematicky výskum na akropoli v Smoleniciach-Molpíre. Geophysikalische Prospektion und Nachgrabung auf der Hauptburg von Smolenice-Molpír. Študijné zvesti AÚ SAV 47, 2010, 41-51.

S. Müller: Smolenice-Molpír, Sered' und Ratkovce. Studien zu Siedlungen der frühen Eisenzeit in der Südwestslowakei. Universitätsforschungen zur prähistorischen Archäologie 220. Bonn 2012.

H. Parzinger/S. Stegmann-Rajtár: Smolenice-Molpír und der Beginn der skythischen Sachkultur in der Südwestslowakei. Prähistorische Zeitschrift 63, 1988, 162-178.

S. V. Polin: Chronologija rann'oskifs'kich pam'jatok. Archeologija 59, 1987, 17-36. 
Rau 1929

Rolle 1980

Samashev 2007

Smyrnov 1964

Stegmann-Rajtár 1998

Szabó/Czajlik/Remény 2014

Shilov/Ochir-Gorjeva 1997

Terenozhkin 1976

Ünal 1982

Yalçıklı 2009
P. Rau: Die Gräber der Frühen Eisenzeit im unteren Wolgagebiet. Studien zur Chronologie der skythischen Pfeilspitzen. Mitteilungen des Zentralmuseums der Autonomen Sozialistischen Räte-Republik der Wolgadeutschen 1. Pokrowsk 1929.

R. Rolle: Die Welt der Skythen. Stutenmelker und Pferdebogner. Ein antikes Reitervolk in neuer Sicht. Luzern - Frankfurt am Main 1980.

Z. Samashev: Die Fürstengräber des Siebenstromlandes. In: W. Menghin (Hrsg.): Im Zeichen des Goldenen Greifen. Königsgräber der Skythen. München Berlin - New York 2007, 162-170.

K. F. Smyrnov: Savromat'i. Rannjaja istorija i kul'tura Sarmatov. Moskva 1964.

S. Stegmann-Rajtár: Spinnen und Weben in Smolenice-Molpír. Ein Beitrag zum wirtschaftlichen und religiös-kultischen Leben der Bewohner des hallstattzeitlichen Fürstensitzes. Slovenská archeológia 46, 1998, 263-268.

G. V. Szabó/Z. Czajlik/L. Remény: Traces of an Iron Age armed conflict. New Topographical Results from the Research into Verebce-bérc at Dédestapolcsány I. Hungarian Archaeology. E-Journal Spring 2014. http://files.archaeolingua.hu 2014TA/Upload/cikk_Szabo_EN.pdf [27. 11. 2019].

B. P. Shilov/M. A. Ochir-Gorjeva: Kurgan'i skifskoj epoki ie mogil'nikov Aksenovskij I-II. Pamjatniki predskifskogo i skifskogo vremeni na juge Vostochnoj Evrop'i. M., 1997, 127-152.

A. I. Terenozhkin: Kimmerijc'i. Kijiv 1976.

V. Ünal: Zwei Gräber eurasischer Reiternomaden im nördlichen Zentralanatolien. Beiträge zur Allgemeinen und Vergleichenden Archäologie 4, 1982, 65-81.

D. Yalçılı: Hinweise auf eine Pfeilspitzenwerkstatt in der ersten Hälfte des 1. Jahrtausends v. Chr. Prähistorische Zeitschrift 84, 2009, 181-190.

\title{
Písmo jazdeckých nomádskych etník v 1. tisícročí pred Kr.? Poznámky k takzvaným skýtskym hrotom šípov so značkami medzi východnými Alpami, Uralom a Anatóliou
}

\author{
Anja Hellmuth Kramberger - Radoslav Čambal
}

Súhrn

V roku 2002 boli objavené malé ryté značky na piatich kusoch tzv. skýtskych hrotov šípov z opevneného výšinného sídliska Molpír v Smoleniciach na juhozápadnom Slovensku (obr. 1; 2; Hellmuth 2006, 135-137, obr. 107, tab. 22: 1-5). Ako analógie jemných rytých značiek sa uvádzali prvé nálezy hrotov šípov z vylúpeného hrobu v Amasya v blízkosti Ladiku a nález z Boğazköy v Anatólii. Pokračovanie štúdia týkajúceho sa šípov jazdecko-nomádskej kultúry by mohlo poukázat' na d’alšie podobné nálezy v severopontskej oblasti a najmä v oblasti dolného toku Volgy (Hellmuth 2007; 2010, 91 n.).

Skutočnost', že prítomnost’ rytých značiek na hrotoch šípov zo Smoleníc-Molpíra nie je iba výnimkou, je demonštrovaná skupinou doteraz nepublikovaných nálezov. Tridsatpät hrotov šípov tzv. skýtskeho typu s vyrytými značkami bolo identifikovaných spomedzi 753 kusov uložených v súkromnej zbierke, ktoré pochádzajú zo smolenického Molpíra a ktoré boli zdokumentované v Slovenskom národnom múzeu - Archeologickom múzeum v Bratislave (obr. 4). Súbor 35 hrotov s rytými značkami zo smolenického Molpíra je jedným z doteraz najväčších nájdených komplexov svojho druhu. Autori tohto príspevku využívajú túto príležitost' na jednej strane na osvetlenie dalšieho priestorového porovnania (obr. $3 ; 5 ; 6)$ a na druhej strane na prezentáciu typov znakov a ich rozmanitosti variantov k d’alšiemu skúmaniu a interpretáciám.

Celkovo možno podla súčasného stavu výskumu ryté značky na skýtskych hrotoch šípov zo Smoleníc-Molpíra, severopontskej oblasti a Anatólie rozdelit do 14 rôznych skupín (obr. 7: a-o). Prvú skupinu (a) tvoria zárezy, ktoré boli vedené väčšinou horizontálne, zriedkavejšie diagonálne. Najväčšiu skupinu tvoria rovnobežné ryhy (c-h), z ktorých niektoré sa vyskytujú aj v kombinácii s inými znakmi. Tu môžeme rozlíšit medzi horizontálnymi a diagonálnymi rezmi, ktoré boli aplikované bud' na jednej strane, na oboch stranách, alebo aj na niekol'kých krídlach hrotu. Rôzne varianty zahŕňajú skupinu škrabancov, ktoré sú postavené na báze kríža (i, j). Krížový motív sa v celej distribučnej oblasti vyskytuje najčastejšie v najjednoduchšej forme na liste šípu a na tulajke. Ďalšiu skupinu tvoria rezy vyhotovené pod rôznymi uhlami (k), z ktorých najvýraznejším variantom je „vtáčia stopa“. Zo všetkých lineárnych rytých značiek 
poukazujú hadovité línie na prepojenie s distribučnou oblastou dolného toku Volgy. Kurvolineárne ryhy je azda možné interpretovat' ako štylizované zobrazenie reflexného luku.

Porovnania ukazujú, že ide o opakujúci sa pomerne zložitý systém znakov. Jazdecká nomádska kultúra je ako jediná známa z písomných záznamov z doby železnej. Jej nositelia mali koncom 8. a 7. stor. pred Kr. intenzívne kontakty s Asýrčanmi, Frýgmi a Grékmi, ktorí mali vlastnú písomnú kultúru. V prípade niektorých postáv možno nájsț paralely so starogréckymi, ale aj s rôznymi „alpskými“ nápismi etruského okruhu (obr. 8; Haarmann 1998, 455 nn., 456 nn., obr. 318). Vynára sa otázka, či by značky na skýtskych hrotoch šípov nemohli byt๋ tiež istým typom písma, pričom relatívne vel'ké množstvo označení pôsobí tak, že človek myslí menej na fonografické písmo než na logografiu. Podla aktuálneho stavu výskumu však interpretácia značiek na hrotoch šípov ako písma bez lingvistického výskumu ostáva skôr na úrovni špekulácií a je potrebné dúfat', že výskum v budúcnosti vytvorí väčšiu materiálnu základňu. Zároveň je pravdepodobné, že niektoré jemné ryté znaky a značky na nálezoch neboli doteraz rozpoznané.

Obr. 1. Hroty šípov s rytými značkami zo Smoleníc-Molpíra (podla Hellmuth 2006, obr. 107).

Obr. 2. Schematické znázornenie základných typov halštatských trojkrídelkových hrotov šípov s rôznymi rytými značkami zo Smoleníc-Molpíra.

Obr. 3. V texte zmienené náleziská: 1 - Aksjenovskij (Rusko); 2 - Amasya pri Ladiku (Turecko); 3 - Basovka (Ukrajina); 4 - Blumenfeld' Kurgan (Rusko); 5 - Boğazköy (Turecko); 6 - Gumarovský Kurgan (Rusko); 7 - Issyk (Kazachstan); 8 - Kamyšin (Rusko); 9 - Kornijvka (Ukrajina); 10 - Lapasina (Rusko); 11 - Leninsk (Rusko); 12 - Libna (Slovinsko); 13 - Lichačevka (Ukrajina); 14 - Nižnjego Povolž’ja (Rusko); 15 - Pjatmary (Rusko); 16 - Pridneprovka (Ukrajina); 17 - Repjahovataja Mogila (Ukrajina); 18 - Smolenice-Molpír (Slovensko); 19 - Vysokaja Mogila (Ukrajina).

Obr. 4. Ryté značky na hrotoch šípov zo Smoleníc-Molpíra (nepublikované), zdokumentované v Slovenskom národnom múzeu - Archeologickom múzeu v Bratislave.

1 - 131-SM 777; 2 - 153-SM 798; 3 - 158-SM 803; 4 - 170-SM 815; 5 - 5; 6 - 46; 7 - 203-SM 592; 8 - 215-SM 604; 9 - 40429/99; 10 - 424-SM 250; 11 - 443-SM 491; 12 - 518-54/99; 13 - 530-4/2000; 14 - 539; 15 - 541; 16 - 612-18/99; 17 - 65669/2005; 18 - 710; 19 - 721; 20 - 727-SM 459; 21 - 401-20/99; 22 - 438-SM 304; 23 - 470-SM 518; 24 - 471-SM 519; 25 - 474-SM 522; 26 - 477-SM 525; 27 - 480-SM 528; 28 - 523-61/99; 29 - 524-62/99; 30 - 652-64/2005. Súkromná zbierka Smolenice-Molpír.

Obr. 5a. Dvoj- a trojkrídelkové hroty šípov s rytými značkami z Anatólie, dolného Povolžia, južného predpolia Uralu, stredného Podnepria, Sedmohradska a z východoalpskej oblasti.

1 - Boğazköy (Boehmer 1972, tab. 30: 888); 2 - Boğazköy (Boehmer 1972, tab. 30: 895); 3 - Boğazköy (Boehmer 1972, tab. 30: 895); 4 - Boğazköy (Boehmer 1972, tab. 31: 907); 5 - Boğazköy (Boehmer 1972, tab. 31: 917); 6 - Amasya (Ivantchik 2001, obr. 23: 10); 7 - Amasya (Ivantchik 2001, obr. 23: 20, 21, 23, 24, 32-35, 38, 43-44, 48-55, 57-59, 61, 62, 67, 70-73, 75-78, 80-82, 84, 86, 87, 92-94, 133, 144, 147, 151, 161, 165, 166); 8 - Amasya (Ivantchik 2001, obr. 23: 26, 83, 128, 152); 9 Amasya (Ivantchik 2001, obr. 23: 36, 134, 184); 10 - Amasya (Ivantchik 2001, obr. 23: 228); 11 - Amasya (Ivantchik 2001, obr. 23: 134); 12 - Amasya (Ivantchik 2001, obr. 23: 202); 13 - Amasya (Ivantchik 2001, obr. 23: 203); 14 - Amasya (Ivantchik 2001, obr. 23: 204); 15 - Amasya (Ivantchik 2001, obr. 23: 227); 16 - Tejuş (?), múzeum Kluž (Hellmuth 2006, tab. 22: 6); 17 - Basovka (Hellmuth 2010, tab. 24: 18); 18 - Pridneprovka (Hellmuth 2010, tab. 184: 2); 19 - Pridneprovka (Hellmuth 2010, tab. 184: 4); 20 - Korniyvka (Полін 1987, obr. 12: 26); 21 - Kamyschin (?; Rau 1929, tab. 20: 1D); 22 - Nižnjego Povolžja (Hellmuth 2010, tab. 148: 30); 23 - Aksjenovskij (Hellmuth 2010, tab. 4: 15); 24 - Aksjenovskij (Hellmuth 2010, tab. 4: 17; 5: 30; 8: 11; 11: 20, 21, 23); 25 - Aksjenovskij (Hellmuth 2010, tab. 8: 9); 26 - Aksjenovskij (Hellmuth 2010, tab. 4: 18, 19; 11: 54). Ryté značky na hrotoch šípov z rôznych nálezísk. Zobrazené hroty šípov sú „reprezentantmi“ pre jednotlivé základné formy a nepredstavujú originál.

Obr. 5b. Dvoj- a trojkrídelkové hroty šípov s rytými značkami z Anatólie, dolného Povolžia, južného predpolia Uralu, stredného Podnepria, Sedmohradska a z východoalpskej oblasti.

27 - Aksjenovskij (Hellmuth 2010, tab. 5: 32); 28 - Aksjenovskij (Hellmuth 2010, tab. 8: 10); 29 - Aksjenovskij (Hellmuth 2010, tab. 8: 12); 30 - Aksjenovskij (Hellmuth 2010, tab. 11: 24); 31 - Aksjenovskij (Hellmuth 2010, tab. 11: 53); 32 - Blumenfeld' (Hellmuth 2010, tab. 38: 13); 33 - Blumenfeld' (Hellmuth 2010, tab. 38: 14, 16); 34 - Blumenfeld' (Hellmuth 2010, tab. 38: 15); 35 - Pjatimari (Смирнов 1964, obr. 26: 1); 36 - Pjatimari (Смирнов 1964, obr. $44: 1$ druhý rad, 7. sprava); 37-39 - južný Ural, vyryté alebo liate? (Смирнов 1964, obr. 37: 17-19; 39: 8); 40 - Lapasina, vyryté alebo liate? (Смирнов 1964, obr. 43: 2); 41 - Leninsk (Смирнов 1964, obr. 52: 7); 42 - Leninsk (Смирнов 1964, obr. 52: 18); 43 - Libna (Hellmuth 2007); 44 - Gumarovo (Дараган 2015, obr. 6: 1); 45 - Gumarovo (Дараган 2015, obr. 7: 17); 46 - Gumarovo (Дараган 2015, obr. 7: 18); 47 - Glinišče (Дараган 2015, obr. 9: 32); 48 - Glinišče (Дарагaн 2015, obr. 9: 33 ); 50 - Povolž ’e (Дараган 2015, obr. 9: 29); 51 - Žabotin, sídlisko (Дараган 2015, obr. 11: 11); 52 - Žabotin, sídlisko (Дараган 2015, obr. 11: 15). Ryté značky na hrotoch šípov z rôznych nálezísk. Zobrazené hroty šípov sú „,reprezentantmi“ pre jednotlivé základné formy a nepredstavujú originál.

Obr. 6. Dvoj- a trojkrídelkové hroty šípov s liatymi značkami z Anatólie, dolného Povolžia, južného predpolia Uralu a zo stredného Podnepria.

1 - Amasya (Ivantchik 2001, obr. 24: 5-7); 2 - Bogazköy (Boehmer 1972, tab. 31: 902); 3 - Ukrajina (zbierka O. Sprengera); 4 - Novaja Belogorka (Смирнов 1964, obr. 8: 1); 5-8 - Sobolevskij Kurgan (Смирнов 1964, obr. 14: 1); 9 - Mečetsaj (Смирнов 1964, obr. 21: 1a); 10 - Pjatimary (Смирнов 1964, obr. 44: 2); 11-15 - Novoe Zaporož’je (Maхортых/Poлле 2015); 16 - Makeevka (Hellmuth 2010, tab. 126: 14); 17 - Nikol'skoje (Hellmuth 2010, tab. 143: 2); 18-22 - Mamaj-Gora (Андрух 2001, obr. 66: 5; 74: 9; 91: 3); 23 - Erkovc'i (Мозолевский 1975, obr. 2: 10 - In: Skifskij mir); 24 - Ordžonikidze (Тереножкин/Ильинская/Черненко/Мозолевский 1973, obr. 28: 7, 9 - In: Skifskije drevnosti). Zobrazené hroty šípov sú „reprezentantmi“ pre jednotlivé základné formy a nepredstavujú originál. 
Obr. 7. Rôzne skupiny rytých značiek na dvoj- a trojkrídelkových hrotoch šípov tzv. skýtskeho alebo nomádskeho typu na celom území ich rozšírenia.

a - vrypy; b - vpichy; c - (paralelné) horizontálne línie na jednej strane krídelka; d - (paralelné) horizontálne línie na obidvoch stranách krídelka; e - (paralelné) diagonálne, nahor smerujúce línie na jednej strane krídelka; f - (paralelné) diagonálne, nahor smerujúce línie na obidvoch stranách krídelka; g - (paralelné) diagonálne, nadol smerujúce línie na jednej strane krídelka; $\mathrm{h}$ - (paralelné) diagonálne, nadol smerujúce línie na obidvoch stranách krídelka; i, j - kríž; k - uhol; l - dvojitý uhol; m - cik-cak; n - zvislé línie; o - hadovité línie/,reflexné luky“.

Obr. 8. „Alpské“ nápisy etruského písomného kultúrneho okruhu v mladšej dobe železnej (podla Haarmann 1998).

Obr. 9. Prekreslený nápis na striebornej miske z kurgana v Issyku, Kazachstan (podl’a Samašev 2007).

Obr. 10. Írske oghamové písmo (ogham; podla Haarmann 1998).

Preložil Radoslav Čambal

doc. Dr. Anja Hellmuth Kramberger

Universalmuseum Joanneum

Eggenberger Allee 90

AT - 8020 Graz

und

Univerza v Ljubljani, Filozofska fakulteta

Oddelek za arheologijo

Zavetiška 5

SI - 1000 Ljubljana

Anja.Hellmuth-Kramberger@ff.uni-lj.si
Mgr. Radoslav Čambal, PhD.

Slovenské národné múzeum - Archeologické múzeum Žižkova 12

SK - 81006 Bratislava

radoslav.cambal@snm.sk 